\title{
Degradation of chlorinated benzaldehydes in aqueous solutions by UV-irradiation
}

\author{
Miray Bekbölet ${ }^{1, \dagger}$ and Nikola Getoff ${ }^{2}$ \\ ${ }^{1}$ Bogaziçi University, Institute of Environmental Sciences, 80815 Bebek-Istanbul,Turkey \\ ${ }^{2}$ Ludwig Boltzmann Institute for Radiation Chemistry and Radiation Biology, \\ University of Vienna, Althanstrasse 14, 1090 Vienna, Austria
}

\begin{abstract}
Photoinduced degradation of chlorinated benzaldehydes was investigated using UV light with $\lambda=253.7 \mathrm{~nm}$ in aerated aqueous solutions. Substrate degradation rate as expressed by first order reaction kinetics revealed rate constants, $\mathrm{k} ; 7.45 \times 10^{-3} \mathrm{~min}^{-1}, 3.90 \times 10^{-3} \mathrm{~min}^{-1}$ and $3.11 \times 10^{-2} \mathrm{~min}^{-1}$ for 2chlorobenzaldehyde, 3-chlorobenzaldehyde and 4-chlorobenzaldehyde respectively. The decomposition of the substrates was related to the formation of chloride and formaldehyde by homolytic cleavage processes. initial quantum yields and photochemical " $\mathrm{G}_{\mathrm{i}}^{\mathrm{PH}}$-values" are reported for the degradation of the substrates. Based on the qualitative HPLC analysis, a probable reaction mechanism for the photoinduced degradation of chlorinated benzaldehydes is also presented.
\end{abstract}

\section{INTRODUCTION}

Halogenated organic compounds are widely used as starting materials for the synthesis of a wide range of industrial chemicals also they may be present as components in various pesticides used in the modern agriculture etc. Their environmental fate may end up by their occurence In the ground water through the infiltration/deep percolation processes of rain and snow water. Therefore, this kind of substances are contained not only in various industrial wastewaters, but occasionaly also in drinking water. They are rather biologically resistant and represent a special class of pollutants, which are also blamed as initiators of cancer and other diseases. Hence, the degradation of such compounds in water was and is still of special interest for many researchers.

One of the major concern about chlorinated benzaldehydes is their persistency following their introduction to the environment via many pathways.This is because they are extremely stable toward acidic or basic hydrolysis or pyrolysis, they are also resistant toward biodegradation, however they are known to be photochemically labile.

Recent literature covers the results of the studies on the presence and toxic effects of the chlorinated benzaldehydes especially the p-isomer. 4-chlorobenzaldehyde was detected as the final product of direct photolysis of thiobencarb (a thiocarbamate insecticide) at $253.7 \mathrm{~nm}$ in air-saturated aqueous solution [1]. The cytotoxicity of aqueous chlorination products of thiobencarb including 4-chlorobenzaldehyde were also reported [2]. 4-chlorobenzaldehyde was also detected as one of the main by-products of aerobic degradation

${ }^{\dagger}$ E-mail: bekbolet@boun.edu.tr of DDT, a world wide used insecticide that was banned several years ago but it is still in use in underdeveloped countries since it is accepted to be the major agent for the eradication of malaria.

During water purification of river or raw water for an end use as tap water supply, chlorinated benzaldehydes were detected upon degradation of pesticides via chlorination. Therefore, the management and control of pesticides in drinking water should also include testing of chlorination by-products such as chlorinated benzaldehydes other than trihalomethanes [3, 4].

Literature data concerning the radiolytic/photochemical behaviour of chlorinated benzaldehydes are very rare. It has been previously found by pulse radiolysis in airfree, aqueous solutions of benzaldehyde (BA) as well as of the o-, m-, and p-isomers chlorobenzladehydes, that the solvated electrons $\left(\mathrm{e}_{\mathrm{aq}}^{-}\right)$do not attack the $\mathrm{Cl}$-atom as should be expected, but the carbonyl group specifically [5]. The authors reported the $\mathrm{p} K$-values as well as the kinetic and spectroscopic characteristics of the corresponding transients and of the $\mathrm{H}$-adducts. On the other hand, it was observed that the radiation induced ( $\gamma$-rays) degradation of 2-chlorobenzaldehyde, 3chlorobenzaldehyde and 4- chlorobenzaldehyde in neutral, and oxygenated aqueous solutions showed that the position of the $\mathrm{Cl}$-atom on the aromatic ring was a determining factor for the initial OH-attack [6]. The initial G-values $\left(\mathrm{G}_{\mathrm{i}}\right)$ for the decomposition of the three substrates were found to be in an increasing order of 3-chlorobenzaldehyde (0.72), 2-chlorobenzaldehyde (1.45) and 4-chlorobenzaldehyde (2.65). The $\mathrm{G}_{\mathrm{i}}$-yields of the major products, such as chloride ions, formaldehyde, and mixture of carboxylic acids were also determined. The same authors [7] studied the photocatalytic oxidative degradation of the same substrates under the influence of monochromatic UV-light $(\lambda=253.7 \mathrm{~nm})$ 
using $\mathrm{TiO}_{2}$ in rutile crystal form as the photocatalyst. The degradation process of the substrates was followed as a function of the absorbed UV-light by HPLC-analysis. The initial quantum yields $\left(\mathrm{Q}_{\mathrm{i}}\right)$ of 2-chlorobenzaldehyde, 3-chlorobenzaldehyde, and 4chlorobenzaldehyde were determined as $0.21,0.28$ and 0.29 , respectively. Also, the formation of the major products $\left(\mathrm{Cl}^{-}\right.$ions, formaldehyde, and organic acids) were reported. In a comparative study on the oxidative degradation of 4-chlorobenzaldehyde, photolysis at $(\lambda=253.7 \mathrm{~nm}$, ozonation and combination of both methods was performed [8]. The concentration of 4chlorobenzaldehyde and ozone in the neutral, aqueous solution was varied. It was found that with the increase, the concentration of substrate and of ozone, also the $\mathrm{Q}_{\mathrm{i}}$-value of degradation and product formation rised. Based on the degradation efficiency of the three methods and on the resulting final products (HPLC-analysis of formic, oxalic, glyoxalic, fumaric, malonic, benzoic and 4-chlorobenzoic acids, in addition to formaldehyde and $\mathrm{Cl}^{-}$ions) it was established that the synergistic effect of UV-light and ozone is leading to a very high efficiency of the 4-ClBzA-degradation.

The objective of this paper is concerning the photoinduced degradation of 2-chlorobenzaldehyde, 3chlorobenzaldehyde and 4-chlorobenzaldehyde in air saturated, aqueous solutions using monochromatic UVlight $(\lambda=253.7 \mathrm{~nm} ; E=4.87 \mathrm{eV} / \mathrm{h} v)$. The substrate degradation and the formations of the major products, chloride ions and formaldehyde were followed as a function of the absorbed quanta to assess the degradation process. Kinetic evaluation of the data were presented in terms of initial quantum yields $\left(\mathrm{Q}_{\mathrm{i}}\right)$, initial photochemical $G$-values $\left(G_{i}^{p h}\right)$ as well as the first order kinetic model parameters. Based on the obtained results related to the products, a probable reaction mechanism is also suggested.

\section{METHODOLOGY}

2.1. Light source and actinometry. Batch experimets were performed in a photoreactor composed of a spherical $4 \pi$-quartz immersion type vessel having a volume for the solution of about $100 \mathrm{~mL}$ [9]. The irradiation of the photoreactor was obtained by a low pressure mercury lamp (Osram HNS $10 \mathrm{~W}$ with incorporated Vycor-filter for the removal of the $185 \mathrm{~nm}$ line) providing monochromatic UV-light at wavelength $\lambda=253.7 \mathrm{~nm} ; E=4.87 \mathrm{eV} / \mathrm{h} v$. The lamp was placed in a quartz immersion cell in the central axis of the reactor. Cooling was provided by the circulation of water through the outer chamber of the reactor. All of the UV experiments were carried out at $31.5^{\circ} \mathrm{C}$.

Monochloroacetic acid actinometer was used to determine the absorbed UV-light quanta under the specified experimental conditions [10]. An air saturated solution of monochloroacetic acid $(0.5 \mathrm{M})$ was prepared in triple distilled water. The results of the replicate experiments revealed the light intensity as $\mathrm{I}_{0}=6.44 \times$ $10^{16} \mathrm{~h} v \mathrm{~mL}^{-1} \mathrm{~min}^{-1}$ for an optical path length of $1.0 \mathrm{~cm}$, taking Q for $\mathrm{Cl}^{-}$as 0.36 at $31.5^{\circ} \mathrm{C}$. The starting solutions of 2-chlorobenzaldehyde, 3-chlorobenzaldehyde and 4-chlorobenzaldehyde were saturated with air and irradiated at the same temperature.

\subsubsection{Materials}

The substrates, 2-chlorobenzaldehyde (2-ClBzA), 3-chlorobenzaldehyde (3-ClBzA) and 4-chlorobenzaldehyde (4-ClBzA) p.a. quality were supplied either by Fluka or Merck and used as received. The expected degradation products; such as, benzaldehyde, 2-chlorophenol, 4-chlorophenol, 4-hydroxybenzaldehyde, and 5-chlorohydroxybenzaldehyde were supplied as commercial compounds (purity: $\geq 98 \%$ ) and used as received. The aqueous solutions containing an appropriate amount of the substrate in the desired concentration (or concentration range; $0.1 \mathrm{~m} \mathrm{M}$ $1.0 \mathrm{~m} \mathrm{M}$ ) were prepared using triple distilled water. Dissolution of the substrates were achieved by means of ultrasonic agitation.

\subsubsection{Experimental procedure}

$100 \mathrm{~mL}$ of aerated $\left(0.25 \mathrm{mM}, \mathrm{O}_{2}\right)$ aqueous solution of $0.1 \mathrm{mM}$ substrate was placed in the reaction vessel. The solution was stirred by a magnetic stirrer providing complete mixing throughout the experiments. UVlamp was stabilized for 30 minutes prior to the start of the irradiation experiment. The reaction was carried out at the natural solution $\mathrm{pH}$ values $\left(\mathrm{pH}_{\mathrm{i}} \approx 6.8\right)$. Periodic sampling was provided by withdrawing samples through the sampling ports. Duplicate photolysis experiments were performed and the results of the replicate product analyses were presented.

\subsubsection{Analytical procedures}

Substrate degradation was followed by spectrophotometric measurements by using Perkin Elmer, Lambda 16 spectrophotometer. The molar absorption coefficients $\left(\varepsilon, \mathrm{M}^{-1} \mathrm{~cm}^{-1}\right)$ of 2-ClBzA, 3-ClBzA and 4-ClBzA at $253.7 \mathrm{~nm}$ are: 15000,11100 , and 16300 , respectively. The absorption spectra of the substrates exhibits the absorption maximum values at (max: 252.4, 249.2 and $259.6 \mathrm{~nm}$, respectively. The yield of chloride was determined by the mercury-thiocyanate method [11]. Formaldehyde formation was followed by means of the Hantzsch method [12]. The pH-change of the irradiated solution was measured by a pH-meter (Radiometer PHM 64).

The degree of substrate decomposition and the identification of the major photolytic products were performed by HPLC-method (Hewlett Packard 1050 Liquid chromatograph; column: $125 \times 4 \mathrm{~mm}$, id. $5 \mu \mathrm{m}$, 
Hypersil ODS column, solvent mixture: $60 \%$ water containing $3 \% \mathrm{H}_{3} \mathrm{PO}_{4}$ and $40 \%$ methanol; flow rate: $1.0 \mathrm{mLmin}^{-1}$, temperature: $30^{\circ} \mathrm{C}$ ). A multiple wavelength detector was used at 250, 225 and $210 \mathrm{~nm}$. Standard samples of 2-ClBzA, 3-ClBzA and 4-ClBzA were purified by double crystallization, whereas the standard samples of the probable products listed above were used as received.

2.2. Kinetics of photodecomposition. The rate of photodecomposition depends on two factors: (1) the rate of the light absorption and (2) the efficiency of the absorbed photons inducing the degradation process, having a quantum yield $\left(\mathrm{Q}_{\mathrm{i}}\right)$ under given experimental conditions,

$$
\mathrm{Q}_{\mathrm{i}}=\frac{\text { Number of decomposed } / \text { formed molecules }}{\text { Number of absorbed quanta }}
$$

The use of initial photochemical $G$-value $\left(G_{i}^{\text {ph }}\right)$ gives access to the direct comparison between the rates of the advanced oxidation methods applied by $\gamma$-radiolysis and photochemical oxidation as well as photocatalytic oxidation provided that monochromatic light source is used. Based on the absorbed energy per quanta: $E=4.87 \mathrm{eV} / \mathrm{h} v$ for $253.7 \mathrm{~nm}$, the photochemical $\mathrm{G}^{-}$ value $\left(G_{i}^{p h}\right)$ can be calculated:

$$
\mathrm{G}_{\mathrm{i}}^{\mathrm{ph}}=\frac{\text { Number of the decomposed/formed molecules }}{100 \mathrm{eV} \text { absorbed energy }}
$$

The initial quantum yield $\left(\mathrm{Q}_{\mathrm{i}}\right)$ and the initial photochemical $G$-value $\left(G_{i}^{\text {ph }}\right)$ are calculated from the tangents of the corresponding curves.

The widely used kinetic model for the photoinduced degradation of the substrates can be explained by the first order rate equation (3):

$$
\mathrm{R}=-\frac{\mathrm{d}[\mathrm{C}]}{\mathrm{dt}}=\mathrm{k} \cdot[\mathrm{C}]
$$

where;

$\mathrm{R}$ : first order reaction rate $\left(\mathrm{M} \mathrm{min}^{-1}\right)$,

$\mathrm{C}=$ concentration of a given substrate $(\mathrm{M})$,

$\mathrm{t}=$ irradiation time ( $\mathrm{min})$,

$\mathrm{k}=$ first order reaction rate constant $\left(\mathrm{min}^{-1}\right)$

Semilogarithmic graphs of the concentration of the substrates should yield straight lines for reaction times with a slope of reaction rate constant, $\mathrm{k}\left(\mathrm{min}^{-1}\right)$. The half-time of the reaction $\left(t_{1 / 2}, \mathrm{~min}\right)$ is also determined by applying the following equation (4):

$$
\mathrm{t}_{1 / 2}=\frac{0.693}{\mathrm{k}}
$$

The degradation of the substrates were expressed in terms of $\mathrm{Q}_{\mathrm{i}}, \mathrm{G}_{\mathrm{i}}^{\mathrm{PH}}$ and first order rate parameters as $\mathrm{k}$ and $\mathrm{t}_{1 / 2}$.

\section{RESULTS AND DISCUSSION}

3.1. Photo-induced decomposition of the substrates. The irradiation time dependent UVabsorption spectra of the substrates were followed. The decrease in the concentration of the substrates could be followed by the changes in the absorption spectra. The observed concentration decrease due to the photolytic degradation of the substrates as a function of the absorbed UV-dose is given in Figure 1. The degradation of 4-ClBzA was comparatively faster than the degradation of 2-ClBzA and 3-ClBzA. For an irradiation time of $20 \mathrm{~min}$ that is equivalent to an absorbed dose of $1.5 \times 10^{18} \mathrm{~h} v \mathrm{~mL}^{-1}$, almost $50 \%$ of 4 -ClBzA was removed whereas only $15 \%$ of 2 -ClBzA and minute amount of $(<5 \%) 3$-ClBzA were removed. During the early stages of irradiation 3-ClBzA exhibited a lag phase lasting up to the absorption of a dose of $5 \times 10^{17} \mathrm{~h} v \mathrm{~mL}^{-1}$ for the initiation of the degradation in comparison to the other isomers. At this stage almost $17 \%$ of 4 -ClBzA and $10 \%$ of 2 -ClBzA were already degraded. The apparent initial quantum yield value was determined from the slope of the tangent at the initial point of the curve which represents the change in the absorption value of the compound versus the absorbed dose (Table 1). The photochemical degradation of 4-ClBzA exhibited the highest yield, $\mathrm{Q}_{i}=0.018$ than the other isomers. Comparatively slower reaction rates were observed for 2-ClBzA and 3-ClBzA. Obviously, the $G_{i}^{p h}$ values followed the same sequence as 4-ClBzA, 2-ClBzA and 3-ClBzA (Table 1). The initial quantum yields $\left(\mathrm{Q}_{\mathrm{i}}\right)$ as well as the initial photochemical G-values $\left(G_{i}^{\text {ph }}\right)$ are found to be essentially lower compared with Gi-yields obtained by $\gamma$-rays induced degradation process [6]. On the other hand, no significant difference in the $\mathrm{Q}_{\mathrm{i}}$ values were reported for the monochromatic $(\lambda=253.7 \mathrm{~nm})$ photocatalytic degradation of the chlorobenzaldehyde isomers [7].

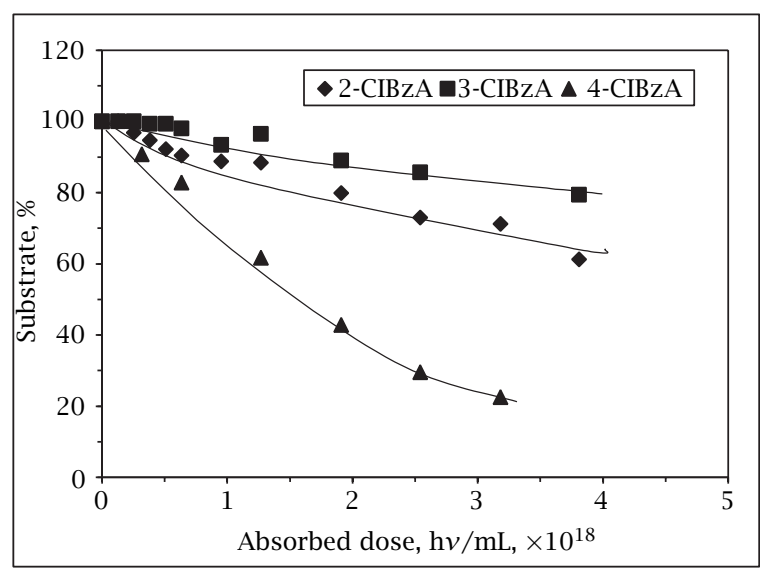

Figure 1. Photoinduced degradation of $0.1 \mathrm{mM}$. 2-ClBzA, 3ClBzA and 4-ClBzA in aerated aqueous solution as a function of absorbed dose. 
Table 1. Initial quantum yield, $\left(\mathrm{Q}_{\mathrm{i}}\right)$ and Initial photochemical yield $\left(\mathrm{G}_{\mathrm{i}}^{\mathrm{PH}}\right)$ values for substrate degradation, chloride formation yield and formaldehyde formation yield of 2-ClBzA, 3-ClBzA and 4-ClBzA.

\begin{tabular}{lcc}
\hline Substrate degradation & Initial quantum yield, $\mathrm{Q}_{\mathrm{i}}$ & Initial photochemical yield, $\mathrm{G}_{\mathrm{i}}^{\mathrm{PH}}$ \\
2-ClBzA & & 0.113 \\
3-ClBzA & 0.006 & 0.071 \\
4-ClBzA & 0.008 & 0.373 \\
Chloride formation & 0.018 & 0.040 \\
2-ClBzA & & 0.0024 \\
3-ClBzA & 0.0020 & 0.050 \\
4-ClBzA & 0.0012 & 0.045 \\
Formaldehyde formation & 0.0024 & 0.021 \\
2-ClBzA & & 0.074 \\
3-ClBzA & 0.002 & 0.001 \\
4-ClBzA & 0.004 & \\
\hline
\end{tabular}

The application of the first order kinetic model to the degradation data revealed the related rate constants The decomposition rate, (Rate $=\mathrm{k}\left[\mathrm{C}_{\mathrm{i}}\right]$ ) of 4 ClBzA was found to be significantly higher than the $\mathrm{o}^{-}$and $\mathrm{m}$-isomers as $3.11 \times 10^{-3} \mathrm{mM} \mathrm{min}^{-1}, 7.45 \times$ $10^{-4} \mathrm{mM} \mathrm{min}^{-1}$ and $3.90 \times 10^{-4} \mathrm{mM} \mathrm{min}^{-1}$ respectively. The corresponding half life values were $22 \mathrm{~min}$, $93 \mathrm{~min}$ and $178 \mathrm{~min}$ for 4 -ClBzA, 2-ClBzA and 3-ClBzA expressing relatively slower degradation rate of 3 ClBzA with respect to the rate observed for 4-ClBzA.

To assess the effect of the initial concentration of the substrate on the photo-induced degradation of chlorinated benzaldehydes experiments were performed in the concentration range of $0.1 \mathrm{mM}-1.0 \mathrm{mM}$. The degradation of the substrates were evaluated in terms of the first order reaction kinetic model and the obtained rate constants $\left(\mathrm{k}_{\mathrm{i}}\right)$ were compared with respect to the $\mathrm{k}$ value obtained for $0.1 \mathrm{mM}$ concentration (Figure 2).

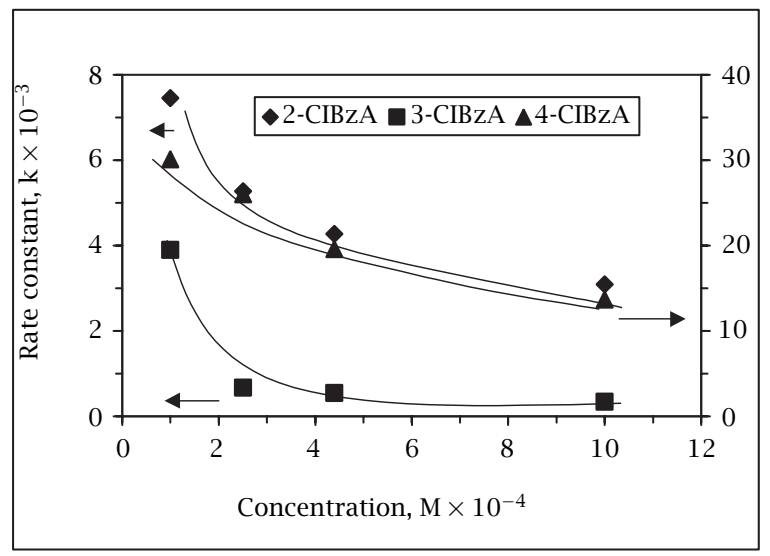

Figure 2. Effect of initial substrate concentration on first order rate constants of photoinduced degradation of 2-ClBzA, 3-ClBzA and 4-ClBzA.

Ten fold increase in initial substrate concentration reflected as a deceleration factor, $\mathrm{f}_{\mathrm{D}}=\left(\mathrm{k}_{\mathrm{i}}-\mathrm{k}\right) / \mathrm{k}$ of 0.58, 0.92 and 0.55 for 2-ClBzA, 3-ClBzA and 4-ClBzA respectively. The half-life values increased dramatically with respect to increasing initial concentration of 3 ClBzA, practically explaining almost non-reactivity of the $\mathrm{m}$-isomer. The lag phase observed for the initial stages of the degradation of 3-ClBzA increased with respect to an increase in the initial concentration probably due to the insufficient rate of photon absorption.

The initial concentration dependency of the reaction rate may address to the case that the reaction follows several possible pathways rather than direct photolytic degradation. It is possible that, photodegradation of chlorinated benzaldehyde isomers is partly caused by free- radical reactions involving hydroxyl and hydroperoxyl radicals. Therefore, the rate law of ClBzA decomposition deviates from first order reaction rate model as limited by the concentration of these oxidizing species. The rate constants obtained by fitting the concentration vs time plots are of course dependent on reactor geometry, illumination intensity and so on, but were internally reproducible.

\subsubsection{Photo-induced decomposition products}

The decomposition process of the three substrates was also followed by the yields of the primary photolytic products as chloride and formaldehyde, formed by homolytic cleavage of the substituents on the aromatic ring. During the photolysis of the chlorobenzaldehydes a strong pH-decrease was also observed, resulting from the formation of organic acids in addition to the $\mathrm{Cl}^{-}$ions.

\subsubsection{Formation of Chloride}

The formation of chloride ions was followed as a function of the absorbed UV-quanta and is presented in Figure 3. The calculated initial yields, $\mathrm{Q}_{\mathrm{i}}$ and $\mathrm{G}_{\mathrm{i}}^{\mathrm{ph}}$, of $\mathrm{Cl}^{-}$yields are given in Table 1 . The highest $\mathrm{Cl}^{-}$formation yield was observed for 2-ClBzA upon absorption of light for about $60 \mathrm{~min}$ with a dose rate of $\mathrm{I}_{0}=$ $6.44 \times 10^{16} \mathrm{~h} v \mathrm{~mL}^{-1} \mathrm{~min}^{-1}$. Due to the presence of a lag phase in the early stages of degradation of 3-ClBzA, extremely low chloride concentrations were detected that may be considered as insiginificant. As an overall view, the lowest $\mathrm{Cl}^{-}$yield was recorded for 3-ClBzA and 


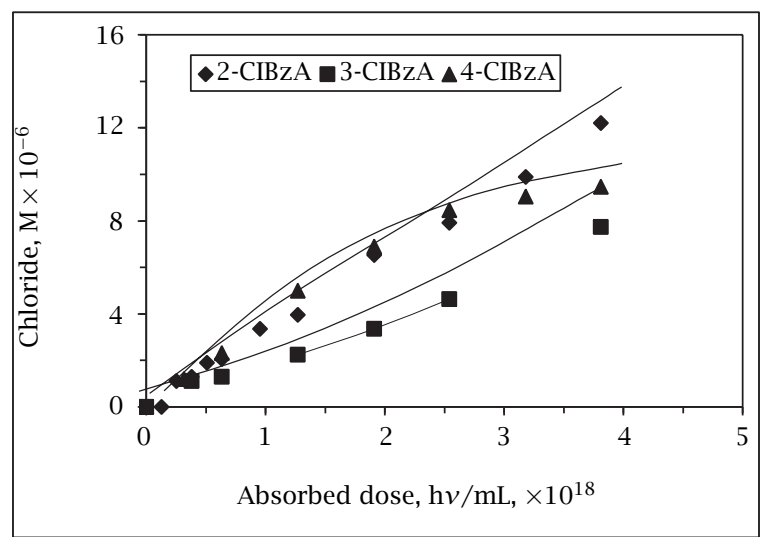

Figure 3. Formation of chloride from 2-ClBzA, 3-ClBzA and 4-ClBzA with respect to absorbed dose in air saturated aqueous solution.

slightly higher yield was obtained for 4-ClBzA. These results indicate that o-position is more succeptible for homolytic cleavage resulting in free chloride ions in reaction medium. On the other hand, this much $\mathrm{Cl}^{-}$concentration corresponds only to $12 \%$ decomposition of the parent molecule and the actual difference in the $\mathrm{Cl}^{-}$releasing capacity of the isomers is in the range of $7.74-12.2 \%$.

Based on the reported results for the degradation of the substrates, photocatalytic $\mathrm{Q}_{\mathrm{i}}\left(\mathrm{Cl}^{-}\right)$[7] and the radiolytic $\mathrm{G}_{\mathrm{i}}\left(\mathrm{Cl}^{-}\right)$taken from [6] the highest yields are obtained for 4-ClBzA, followed by those from 2-ClBzA and 3-ClBzA.. The observed photocatalytic $\mathrm{Q}_{\mathrm{i}}\left(\mathrm{Cl}^{-}\right)$and radiolytic $\mathrm{G}_{\mathrm{i}}\left(\mathrm{Cl}^{-}\right)$values are essentially higher than the photochemical yields.

\subsubsection{Formation of formaldehyde}

The UV-dose dependence of the formaldehyde formation upon irradiaton in the presence of air is given in Figure 4 . The curves were found to be significantly different from each other, where 4-ClBzA exhibits the highest yield of $\mathrm{HCHO}$ with respect to the other two substrates (Table 1). For an absorbed dose of $2.0 \times 10^{18} \mathrm{~h} v \mathrm{~mL}^{-1}$ the highest HCHO formation was achieved for 4-ClBzA, followed by 2-ClBzA and 3ClBzA. Further irradiation did not cause a substantial increase in the $\mathrm{HCHO}$ yield resulting from 4-ClBzA at $3.8 \times 10^{18} \mathrm{~h} v \mathrm{~mL}^{-1}$, almost the same amount of $\mathrm{HCHO}$ was found for both, 2-ClBzA and 4-ClBzA. For 3-ClBzA excluding the lag phase, a steady increase of the aldehyde formation was observed and for the absorbed dose of $3.8 \times 10^{18} \mathrm{~h} v \mathrm{~mL}^{-1}$ the yield of HCHO formation was approximately $10 \%$ of the decomposed 4 -ClBzA. The relative tendency of formaldehyde formation follows the sequence: 4 -ClBzA $>2$-ClBzA > 3-ClBzA. The same trend was also valid for the photocatalytic [7] and radiolytic [6] formaldehyde formation yields for the $\mathrm{p}$-, $\mathrm{o}$ - and m-isomers.

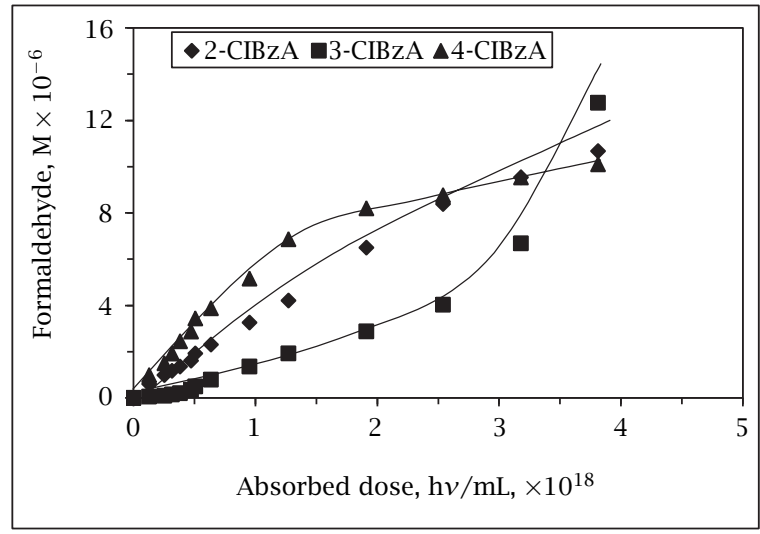

Figure 4. Formation of formaldehyde from 2-ClBzA, 3ClBzA and 4-ClBzA with respect to absorbed dose in air saturated aqueous solution.

\section{$3.1 .4 \mathrm{pH}$}

As a result of the oxidative photoinduced decomposition, a pH decrease was observed with increasing the absorbed dose indicating the formation of acidic compound. For an absorbed dose of $2.0 \times 10^{18} \mathrm{~h} v \mathrm{~mL}^{-1}$ a $\mathrm{pH}$ value of $\approx 4.5$ was reached for all of the substrates. Furher irradiations up to $60 \mathrm{~min}$ resulted in different final $\mathrm{pH}$ values as 3.8 for 2-ClBzA, 4.13 for 3-ClBzA. No further reduction in $\mathrm{pH}$ was observed for 4-ClBzA upon absorption of irradiation as $3.77 \times 10^{18} \mathrm{~h} v \mathrm{~mL}^{-1}$. The $\mathrm{pH}$ drop was followed for up to $180 \mathrm{~min}$ corresponding to $1.16 \times 10^{19} \mathrm{~h} v \mathrm{~mL}^{-1}$ absorbed dose and 3.8 was recorded for 3-ClBzA. Different trends observed in $\mathrm{pH}$ changes with respect to the isomers may express the formation of the carboxylic acids as well as the formation of $\mathrm{HCl}$ and $\mathrm{HClO}$ via reactions (17) by $\mathrm{OH}$ radical mediated degradation pathway as will be explained in the following reaction schemes.

\subsubsection{Photodegradation products}

Due to the low degradation efficiencies, qualitative product analysis were performed by HPLC analyses. In addition to the above reported degradation of the substrates and the formation of $\mathrm{Cl}^{-}$ions, formaldehyde and a mixture of acids as a function of absorbed UV-dose, also a number of organic compounds were identified. As such were found: 2-chlorophenol, 4chlorophenol, 4-hydroxybenzaldehyde, benzaldehyde and 5-chlorohydroxybenzaldehyde. Basically all of the substrates revealed the same pool of products. The formation of the aliphatic carboxylic acids through ring opening such as formic acid, oxalic acid and muconic acid and benzoic acid were also reported previously for 4-ClBzA [8]. This fact strongly indicates that the photoinduced degradation of 2-ClBzA, 3-ClBzA and 4ClBzA in the presence of air is a rather complicated process. Obviously, the primarily formed photolytic 
products after reaching a certain upper concentration become involved in a further photochemical process. As a result of this prolonged attack, secondary transients are formed, which are subsequently leading to the formation of further reactive species and so on. All these transients induced from peroxyl radicals formed in the presence of air, are rather unstable and can initiate opening of the aromatic ring, propagation of radical chain reactions and formation of various carboxylic acids and finally degradation up to $\mathrm{CO}_{2}$ [13]. Consequently, a much higher intensity of UV-light should be needed for a satisfactory degradation of the studied chlorinated benzaldehydes under these conditions.

3.2. Primary Reaction Steps. As mentioned above, the observed numerous photolytic products indicate the complexity of the degradation process. Hence for the sake of completeness some primary photoinduced reactions are presented, taking 2-ClBzA as an example.

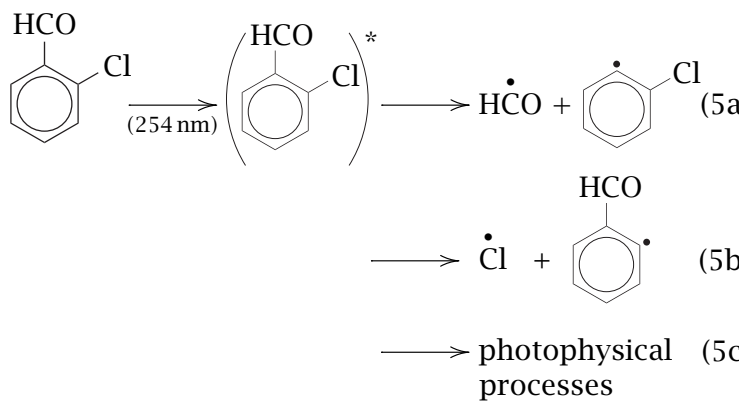

The mechanism involved is thought to be an initial homolytic cleavage of the parent molecule to yield diradical pair (reactions (5a) and (5b)). Practically all carbon centered radicals are expected to be converted by $\mathrm{O}_{2}$ into the corresponding peroxyl radicals. In the presence of air, the formyl radical $\left(\mathrm{HCO}^{\bullet}\right)$ can either undergo disproportionation forming $\mathrm{CO}$ and $\mathrm{HCHO}$ (eq. (6a)), or dimerize to give glyoxal (eq. (6b)) [14].

$$
\begin{gathered}
2 \mathrm{HCO} \longrightarrow \\
\longrightarrow \text { CO }+\mathrm{HCHO} \quad \text { (formaldehyde) } \\
\longrightarrow(\mathrm{HCO})_{2} \quad(\text { glyoxal })
\end{gathered}
$$

In addition to the above reactions $\mathrm{HCO}^{\bullet}$ may undergo the following reactions [15].

$$
\begin{aligned}
\mathrm{HCO} \cdot+\mathrm{O}_{2} \longrightarrow & \mathrm{HCOO}_{2} \bullet \\
2 \mathrm{HCOO}_{2} & (\mathrm{COOH})_{2}+\mathrm{O}_{2} \\
\mathrm{HCO}+\mathrm{H}_{2} \mathrm{O} \longrightarrow & { }^{\circ} \mathrm{CH}(\mathrm{OH})_{2} \\
\cdot \mathrm{CH}(\mathrm{OH})_{2}+\mathrm{O}_{2} \longrightarrow \mathrm{O}_{2} \mathrm{HC}(\mathrm{OH})_{2} & \left(\mathrm{k}=4.5 \times 10^{9} \mathrm{M}^{-1} \mathrm{~s}^{-1}\right) \\
\cdot \mathrm{O}_{2} \mathrm{HC}(\mathrm{OH})_{2} \longrightarrow & \mathrm{HCOOH}+\mathrm{HO}_{2}^{\bullet} \\
& \left(\mathrm{k}=1 \times 10^{6} \mathrm{~s}^{-1}\right)
\end{aligned}
$$

$$
\mathrm{HO}_{2}{ }^{\bullet}<\mathrm{H}^{+}+\mathrm{O}_{2}^{\bullet-} \quad(\mathrm{pK}=4.8)
$$

On the other hand $\mathrm{Cl}^{\circ}$ radical formed from excited substrate molecule (eq. (5b)) can react with water forming $\mathrm{Cl}^{-}$and $\mathrm{OH}$ radicals:

$$
\mathrm{Cl}^{\bullet}+\mathrm{H}_{2} \mathrm{O} \longrightarrow \cdot \mathrm{OH}+\mathrm{Cl}^{-}+\mathrm{H}^{+}
$$

The non-selective reactivity of $\mathrm{OH}$ radical results in various degradation pathways, primarily through the direct attack on the parent molecule and/or by the following reactions.

$$
\begin{gathered}
\mathrm{OH}^{\bullet}+\mathrm{CO} \longrightarrow \mathrm{HCOO}^{\bullet}\left(\mathrm{k}=8.3 \times 10^{8} \mathrm{M}^{-1} \mathrm{~s}^{-1}\right) \\
2 \mathrm{HCOO} \longrightarrow(14) \\
\longrightarrow \mathrm{HCOOH}^{\bullet} \mathrm{CO}_{2} \\
\mathrm{HCOO}^{\bullet} \longrightarrow \mathrm{H}^{+}+{ }^{\bullet} \mathrm{CO}_{2}{ }^{-} \quad\left(\mathrm{pK}_{\mathrm{a}}=1.4\right) \\
\mathrm{CO}_{2}{ }^{-}+\mathrm{O}_{2} \longrightarrow \mathrm{CO}_{2}+\mathrm{O}_{2}{ }^{\bullet}\left(\mathrm{k}=6.5 \times 10^{9} \mathrm{M}^{-1} \mathrm{~s}^{-1}\right) \\
2^{\bullet} \mathrm{CO}_{2}{ }^{-} \longrightarrow(17)
\end{gathered}
$$

Due to the low $\mathrm{pK}_{\mathrm{a}}$ [16] value of $\mathrm{HCOO}^{\bullet}$ with respect to the $\mathrm{pH}$ of the reaction medium, the formation of $\mathrm{H}^{+}$and ${ }^{\bullet} \mathrm{CO}_{2}{ }^{-}$thereby the occurrence of the following reactions (17) and (18) of ${ }^{\bullet} \mathrm{CO}_{2}{ }^{-}$is hindered. Therefore, the $\mathrm{OH}$ radical as well as $\mathrm{HO}_{2} \bullet / \mathrm{O}_{2}{ }^{-}$radicals can initiate further reactions with the substrate leading to the formation of a number of products as evidenced by the presence of the hydroxylated products detected qualitatively by the HPLC analysis. The formations of 4-hydroxybenzaldehyde and 4-chlorophrenol from 4-ClBzA could be detected after the absorption of $1.93 \times 10^{18} \mathrm{~h} v \mathrm{~mL}^{-1}$ in 30 minutes of irradiation time. On the other hand, 2-chlorophenol formation from 2-ClBzA was detected upon absorption of light quanta $1.29 \times 10^{18} \mathrm{~h} v \mathrm{~mL}^{-1}$ lasting up to 40 minutes of irradiation resulting in an absorbed dose of $2.57 \times$ $10^{18} \mathrm{~h} v \mathrm{~mL}^{-1}$. Benzaldehyde formation from 2-ClBzA could be detected following an absorption of quanta as $6.42 \times 10^{17} \mathrm{hvmL}^{-1}$ in 10 minutes, and the presence of this product was detected up to 40 minutes of irradiation period. The formation of benzaldehyde in $40 \mathrm{~min}$ for an absorbed dose of $2.57 \times 10^{18} \mathrm{hvmL}^{-1}$ was detected following a period of 30 minutes during which no product formation was detected from 3ClBzA. The presence of 4-hydroxybenzaldehyde and 4chlorophenol were verified lasting up to 3 hours of irradiation time. In all of the cases, a variety of products with shorter retention times were also detected and the formation of the lower molecular weight carboxylic acids was explained [8].

The reaction mechanism involved in the formation of the above given products could be explained by the following reaction scheme in which 2-ClBzA was given as an example of the substrates. The primary attack of 
the $\mathrm{OH}$ radical on the parent molecule results in the formation of the $\mathrm{OH}$-adduct on o-,m-,p- and ipso positions forming substituted cyclohexadienyl radicals. Secondary reactions may follow various pathways as explained by the reactions (19a) to (19f). Through hydrogen abstraction mechanism, the formation of hydroxybenzaldehyde (19a) and benzaldehyde ((19d) as well as $(5 b)$ ) could be explained. Also, by means of nondestructive hydroxylation of the original ring followed by $\mathrm{O}_{2}$ addition, the formation of chlorohydroxybenzaldehyde could be reasoned out. Besides these, each of the $\mathrm{OH}$-adducts may also lead to the formation of different products which are not furher discussed. As already mentioned above, all organic radicals may be transformed into arylperoxyl radicals via oxygen addition leading to further degradation products. Radical radical addition mechanism resulting in the formation of dimers may also be considered but the occurance of this case was not investigated.

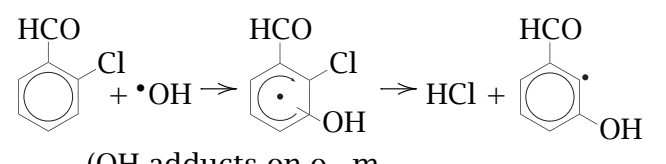

(OH-adducts on $\mathrm{o}^{-}, \mathrm{m}-$, p- and ipso- position)
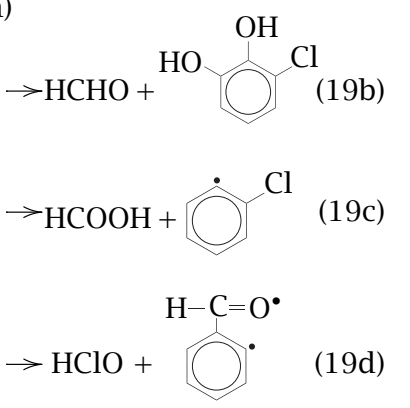<smiles>O=CC1=C(Cl)CC=CC1O</smiles>

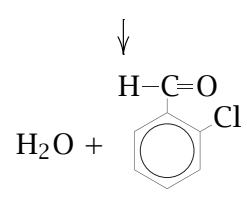

(Regeneration)<smiles>O=CC1=C(Cl)C([18OH])C=CC1[O+]</smiles><smiles>O=C(I)c1ccc(O)cc1Cl</smiles>

\section{CONCLUSION}

Photoinduced degradation of 2-ClBzA, 3-ClBzA and 4-ClBzA was studied using monochromatic UV-light with $\lambda=253.7 \mathrm{~nm}$. The decomposition process of airsaturated solutions of the substrates was followed by chloride and formaldehyde formations. According to the calculated $Q_{i}$ and $G_{i}^{p h}$ values and first order kinetic model, 4-ClBzA revealed the highest yield of decomposition. Strong $\mathrm{pH}$ decrease (formation of acids) was observed for all of the substrates. Photodegradation end products such as 2-chlorophenol, 4-chlorophenol, 4hydroxybenzaldehyde, 5-chlorohydroxybenzaldehyde, benzaldehyde have been identified although could not be quantified due to the low concentrations by HPLC analyses.

\section{ACKNOWLEDGEMENTS}

M. Bekbölet greatly appreciates the financial support provided by the Austrian Exchange Service. M.B. would also like to express her gratitude to the Research Fund of Bogaziçi University.

\section{References}

[1] D. Vialaton and C. Richard, J. Photochem. Photobiol. A-Chem. 136 (2000), 169.

[2] H. Jinno, N. Hanioka, A. Takahashi, T. Nishimura, T. Toyooka, and M. Ando, Toxicology in vitro 11 (1997), 731.

[3] S. Kodama, A. Yamamoto, and A. Matsunaga, J. Agric. Food Chem 45 (1997), 990.

[4] Y. Magara, T. Aizawa, N. Matumoto, and F. Souna, Wat. Sci. Technol. 30 (1994), 119.

[5] S. Solar, N. Getoff, J. Holcman, and K. Sehested, J. Phys. Chem. 99 (1995), 9425.

[6] M. Bekbölet and N. Getoff, Radiat. Phys. Chem. 56 (1999), 333.

[7] M. Bekbölet and N. Getoff, J. Adv. Oxid. Technol. 5 (1998), 162.

[8] A. I. Balcioğlu and N. Getoff, Chemosphere 36 (1998), 1993.

[9] N. Getoff and G. O. Schenck, Photochem. Photobiol. 8 (1968), 167.

[10] M. Neumann-Spallart and N. Getoff, Monatsh. Chem. 99 (1975), 1359.

[11] T. M. Florence and Y. T. Farror, Analyt. Chim. Acta. (1971), 373.

[12] T. Nash, J. Biochem. 55 (1953), 416.

[13] N. Getoff, World Resource Review (1997a), 86.

[14] N. Getoff, Peroxyl radicals in the treatment of water solutions, in Peroxy Radicals, Z. Alfassi (ed.), John Wiley \& Sons, Chishester, 1997b, pp. 483506.

[15] E. Bothe and D. Schulte-Grohlinde, Z. Naturforsch. 15b (1980), 1035.

[16] G. V. Buxton and M. Sellers, J. Chem. Soc. Faraday Trans. 6 (1973), 555. 


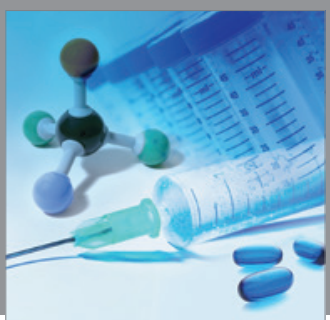

International Journal of

Medicinal Chemistry

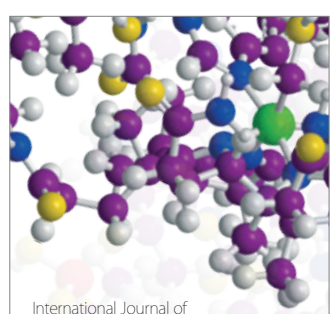

Carbohydrate Chemistry

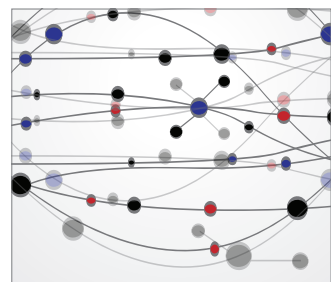

The Scientific World Journal
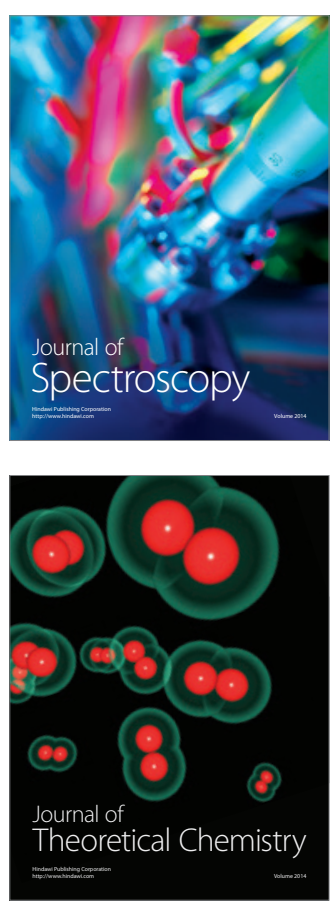
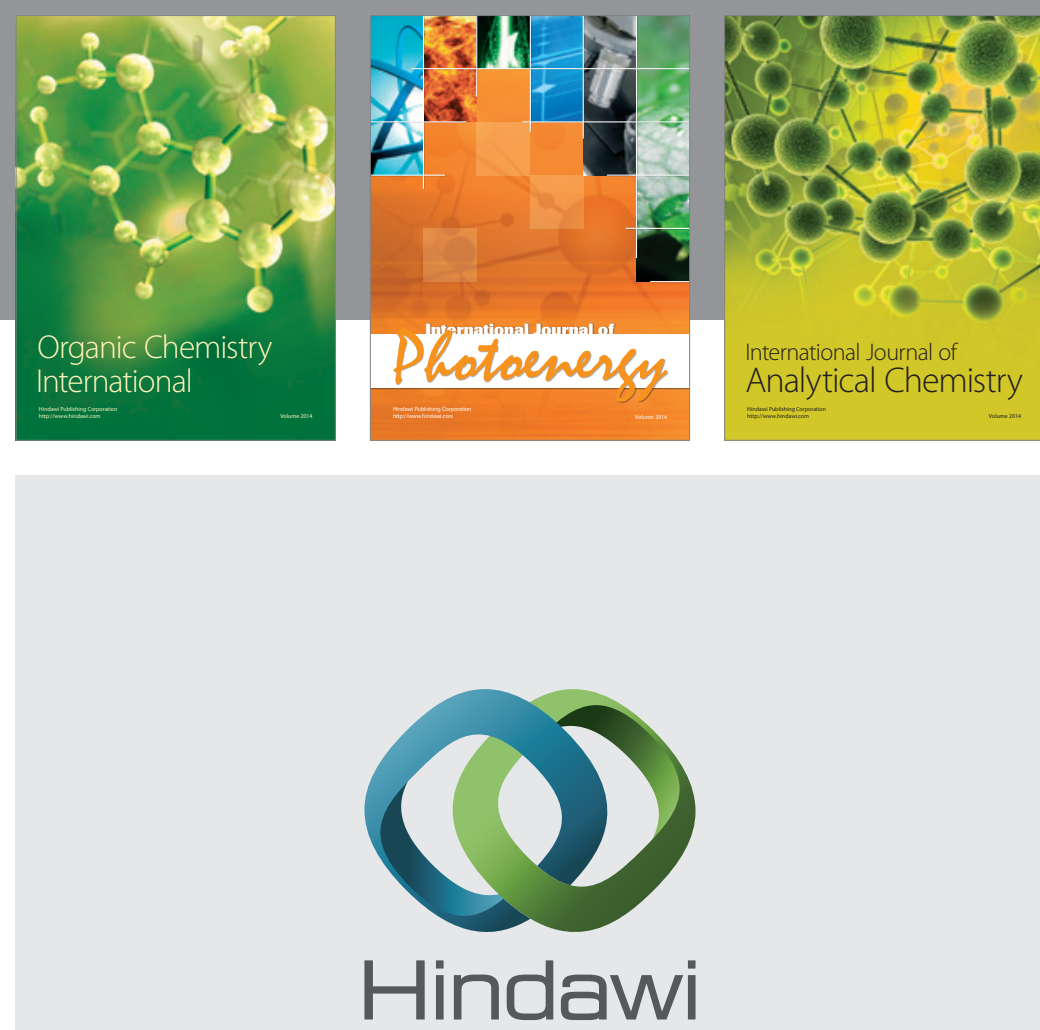

Submit your manuscripts at

http://www.hindawi.com
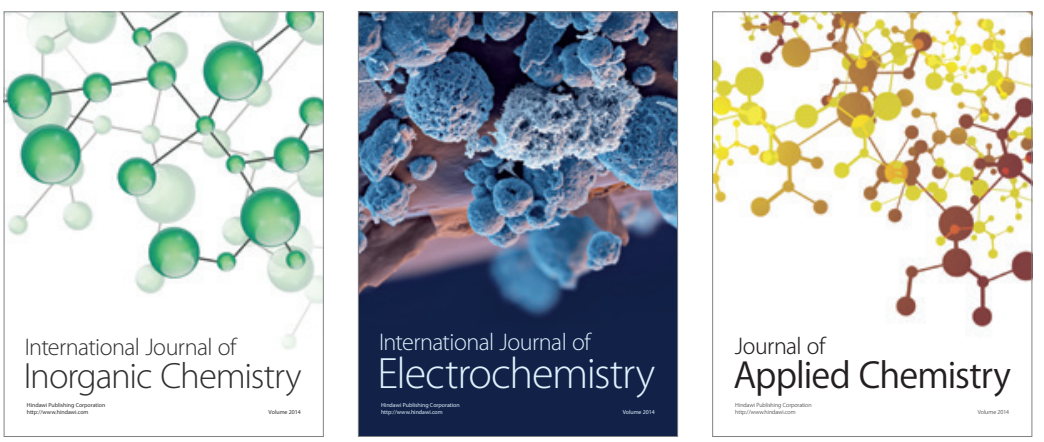

Journal of

Applied Chemistry
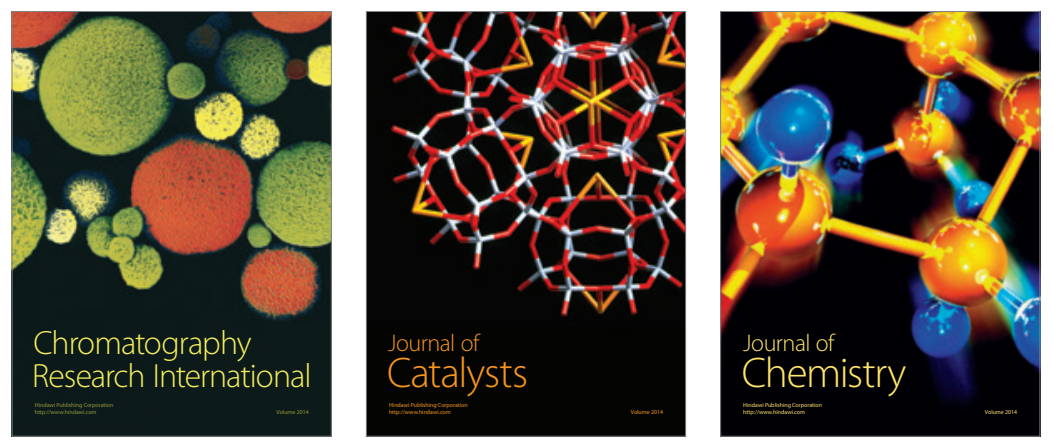
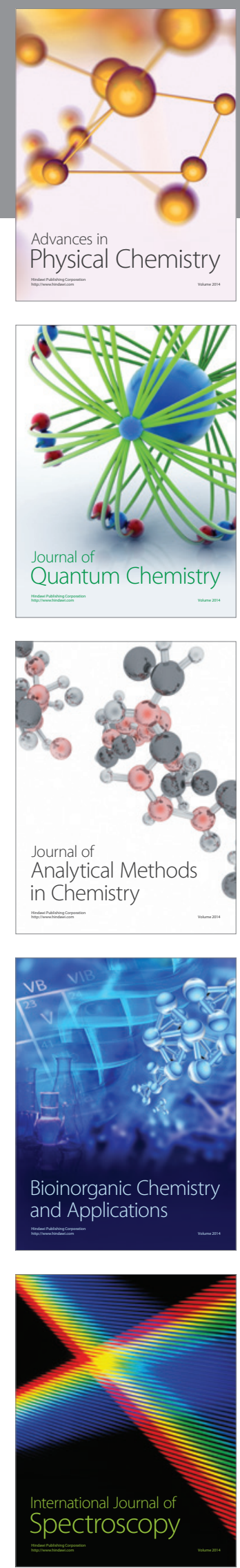